\title{
13 Love and desire, human and divine
}

\author{
A transreligious naturalist \\ account
}

Wesley J. Wildman

\section{Introduction}

Love and desire are profound realities of the very greatest importance to human beings and are critical to narratives defining the meaning of life for our species. Science fiction has imagined self-aware, moral species without love or desire, but they leave me cold. I prefer the passion and energy of love and desire, even allowing for the accompanying problems. Why are these concepts, and the corresponding experiences, so powerful for us, and why do we feel they take us so deeply into the nature of the reality we receive, create, and inhabit? It's a fair question. After all, the cosmos doesn't display a lot of desire until biological complexity reaches a high order, and even in the biological realm desire is a lot more widespread than love, which is as rare in the big scheme of things as it is valuable. Why, therefore, do we human beings sense that love and desire tell us something profound about reality as a whole, rather than merely something profound about ourselves? If there were a divine agent who deliberately created the world out of desire and love, then there would be a basis for inferring something about ultimate reality from human experiences of love and desire. But that line of thinking is for other people to pursue. I'm interested in a transreligious, naturalist account of love and desire, human and divine.

The divine part of such a story refers not to the thoughts, feelings, intentions, or actions of a divine being - not a possibility for the religious naturalist - but to the valuational depth structures and dynamic possibilities of the natural world. Not all naturalists are interested in the axiological (i.e., valuational) depths and flows of natural reality. Yet specifically religious naturalists see in those depths the very ground of being, which they understand to be the correct logical referent of claims that theists make about gods (see Wildman 2017). It follows that peering into those depths for an account of love and desire makes sense as an activity of transreligious theological inquiry. There are touchpoints across the world's religions for such an enterprise, from shamanism of many types to varieties of African traditional religion, from the mystical and philosophical strands within the large religious traditions with sacred canonical literatures, to the formally naturalist or atheist traditions of philosophical reflection. 
The human part of this story, of this transreligious-naturalist account of love and desire, does not refer to the many abstract characterizations of the human person and its destiny or purpose offered within the supernatural worldviews of religions and other wisdom traditions. Rather, the reference is to fully embodied human beings in social worlds realizing some possibilities and foreclosing others in every moment of their fleeting lives, driven by potent desire and its equally insistent companion, aversion. The one universal language we have for communicating across the differences of human bodies, for discussing shared human character under and within human individual and cultural differences, is - no, not the language of love, but the language of science (see Wildman 2009). That's where I'll start this brief meditation, eventually working my way down to divine love and desire in the depths of nature.

\section{Human love and desire}

For centuries, love has been the domain of poets, novelists, and musicians, and in many respects it remains the domain of luminaries within the humanities. But in the last few decades, scientists have taught us a lot about love - not only about the intricacies of the outworkings and failures of love in individual lives but also about the brain and behavioral systems that support the expression of love in the vast majority of human beings across cultures, apparently in much the same way for the last 50,000 years or so (Fisher 2004). These neural-behavioral love systems evolved in other species first, and we see them active in many primate species, though very differently than in human life. There are at least four relatively distinct brain and behavioral love-and-desire systems, three of which are directly related to what we human beings call romantic love (Fisher et al. 2002). Behaviors corresponding to these systems have been discerned in all human cultures, in some cases, and the vast majority of cultures, in other cases, with the exceptions being accounted for by explicit cultural suppression. Never underestimate the capacity of culture to fashion something novel from the givens of biology! It is fair to assume we are talking about biologically universal aspects of human bodies, despite the varied ways that cultures regulate and give expression to them (the key anthropological study is Jankowiak and Fischer 1992). On top of those powerful love-and-desire systems ride intentions that we employ to guide our behavior in accordance with, or possibly in spite of, or even in resistance to, surrounding social norms for regulating this intense domain of human life.

Probably the most fundamental love-and-desire system is maternal love, which is nearly universal across half of each mammalian species. It is critical for mammalian flourishing and, in human beings especially, it has significant overlaps with two of the three types of romantic love and desire to be discussed in what follows (Zeki 2007). Maternal love and sexual attraction are probably the most evolutionarily primal of the four love-and-desire neuralbehavioral love systems - one erotic in nature and the other not. Because 
maternal love is (obviously) not universal in the human species, and because it is fractionated and marshaled by the more romantic and sexual forces of love and desire, I'll set it to one side. In what follows, I focus on the other three love-and-desire systems.

The first of these three love-and-desire systems is sexual attraction. The sexual-attraction system is realized through a mesolimbic neural pathway for which dopamine is the key neurotransmitter, but the sex hormones testosterone and estrogen (and others) are key to activating and regulating this system (Fisher, Aron, and Brown 2006). Love and desire as sexual attraction has no fixed lifespan, but it peaks in late adolescence for males and in the mid-30s for females, waxes and wanes during relationships, and gradually abates through the aging process after the peak is passed. Testosterone levels in human males spike when trying to mate and take a big hit when becoming a father for the first time, so the system reflexively adjusts to some life circumstances. Love and desire in this case refer especially to pleasure seeking and pleasure giving through copulation. The opportunity to mate spurs competition among males, and also among females when sex seems to be on offer, and it spills over into other circumstances as well. In fact, the sexualattraction love-and-desire system is a specialized application of a more general testosterone system that figures in many parts of life, particularly when people are young, and particularly among males, who have less developed self-regulation capabilities than females until their mid-to-late 20s. The testosterone system unleashes a potent set of drives and underwrites a lot of human aggression; indeed, the part of it we call the sexual-attraction system can also cross the line into violence. Unregulated, the sexual-attraction system has the potential to cause social chaos through aggressive rivalries and pregnancies for which people are not ready. Unsurprisingly, this love system is carefully regulated in all human cultures, though in very diverse ways.

The second love-and-desire system is infatuation. Although the tapestry of mate choice is relevant to all sexually reproducing animal species, the infatuation love-and-desire system appears to be a distinctively human thread within that tapestry. The neurochemistry of infatuation within human beings has several dimensions. The feel-good neurotransmitter dopamine plays a critical role, giving us the feeling of intoxication. So does cortisol, which produces anxiety and stress, at least for the first year or two, when we tend to try hardest in new relationships. Higher dopamine is coupled with lower levels of another neurotransmitter, which pushes serotonin down to levels associated with people suffering from obsessive-compulsive disorder and helps to explain why infatuation feels so much like an all-consuming obsession. This neurochemical cocktail also deactivates regions in the frontal cortex that are responsible for being critically minded and able to evaluate evidence fairly, which accounts for the fact that "love is blind" very often and can lead to poor judgment (Zeki 2007). Love and desire as infatuation, once activated in a relationship, has a lifespan of about seven to ten years. A plausible evolutionary explanation for this timeline is that it is just 
long enough to get a couple of children more or less independent and able to help their mother gather protein and carbohydrates for survival. At the most general level, dopamine neural circuits recruit our capacities for valuation, for deciding what is important and directing the focus of our attention. The infatuation love-and-desire system involves distorted valuation in a cloud of longing, whereby we truly only see what we want and need to see in our beloved. A friend could point out our error of judgment, even backed up by solid evidence, and often enough we won't believe it, saying that "you don't know my lover like I do" or some other gloriously and ecstatically self-deluded rationalization for ignoring a lover's well-established patterns of behavior. In Western culture, this is what we mean by being in love immersed in feelings so overwhelming that we experience the desire to possess and to be possessed comprehensively, knowing with certainty that this state of bliss will fulfill all our longings. Of course, we are mistaken in this intoxicated certainty, yet even the mistake bespeaks the depth of longing in life to realize infinite possibilities within the inescapable limitations and ambiguity of the finite.

The third love-and-desire system is bonding. The key neurotransmitters in this case are oxytocin, the so-called "cuddle chemical," and vasopressin; both are powerfully involved in romantic love and maternal love. They are released in large quantities in orgasm and during breastfeeding, triggering potent feelings of closeness, and they are also released in romantic love (Zeki 2007). The bonding system has no lifespan and can actually strengthen as we age, under the right circumstances. We can also destroy progressive bonding with a partner through actions that undermine trust, which is a critical element in maintaining close bonds. In application to love and desire, the bonding love-and-desire system functions in a specialized way to make two, or very few, people extremely tight-knit and loyal. The same system has less specialized applications to groups, where crises or rituals or other processes trigger intensified belonging and loyalty, while underlining the distinction between the in-group, where investment of precious resources in relationships is appropriate, and the out-group, where such investment is inappropriate (Choi 2011; De Dreu et al. 2011). That is, in solidifying closeness and loyalty, the bonding love-and-desire system also solidifies in-group identification against outsiders and amplifies both sensitivity to betrayal perpetrated by in-group members and suspicion toward strangers.

The fact that we human beings bear in our very bodies three biologically distinct love-and-desire systems is extremely important in many domains of human life, including the following four.

First, psychologically, these love-and-desire neurobehavioral systems are emotionally powerful and directly relevant to our everyday worlds. For example, it is critical to realize that the inevitable waning of infatuation need not be the end of romantic love in the other two senses. Plenty of couples experience incredibly potent feelings of shattered dreams, unmet longings, 


\section{2}

Wesley J. Wildman

and associated resentment and grief a few years into a relationship. Indeed, across cultures permitting divorce, the peak divorce rate occurs four to five years into marriage, which is about seven to nine years into the relationship, as the last trace of infatuation evaporates (Fisher 1992). Instead of blaming one another for not living up to the ridiculous expectations we built in a haze of infatuation, it'd be smarter and kinder to recognize the inevitability of this process, to reset expectations, and to focus on strengthening the bonding system and nurturing sexual attraction.

Second, socially, the very same systems that underwrite love also reinforce in-group identities and support energetic monitoring of group boundaries to protect in-groups from outsiders. That is, the flip side of the biochemistry of bonding is xenophobia and racism. Both are biochemically spontaneous processes within human social environments. We do not have to be slaves to such emotional reactions because we can exercise determination and empathy to behave differently. But we certainly are biologically predisposed toward tight bonding with conspecifics and suspicion of strangers.

Third, politically, many of these dynamics operate silently, in nonromantic situations, including just below the surface of political conflict. For instance, they render us vulnerable to lazy acceptance of the incomprehensibility of our political opponents - "we'll just never understand how they could think that way, so there's no point in even talking about it." The result can be the collapse of civility in our public discourse and the damaging of our corporate problem-solving capacities. But some degree of awareness of how these neurobehavioral systems work could mitigate such problems.

Fourth, religiously, there are many ways of regulating or adapting these potent biobehavioral forces. For example, some conservative communities seem terrified of human bodies when it comes to managing the sexualattraction love-and-desire system, excoriating young people for making out or masturbating, while simultaneously successfully activating the bonding love-and-desire system to strengthen suspicion of outsiders and sparking the infatuation system to apply to the many invisible beings of religious devotion. Meanwhile, some liberal religious communities delusionally pronounce their unlimited openness to all people, proclaiming universal acceptance, while remaining utterly oblivious to the very real social and psychological conditions for bonding and completely failing to see how exclusionary their behavior seems to those who are more realistic about the conditions for forming group identity, as many conservatives are. I'm pretty sure the conservative religious grip on the human love systems does more damage, if only because they're the ones who bring the most people into the world of their religious stories through activating bonding and infatuation circuitry for religious ends. Meanwhile, liberal religious communities are uncomfortable with too much emotionality and rightly suspicious of the dangers of in-group-out-group boundaries, so they refuse to avail themselves of the biochemical pathways to congregational flourishing that 
conservative communities employ. In our time, those liberal communities are withering on the vine.

Those four applications of the human love-and-desire systems are sufficient to make the point that knowing about our three neurobehavioral love systems matters. In particular, we need to understand that they are portable, in the sense that they are applicable not only proximally to love but also distally to out-group suspicion, religious devotion, purchasing patterns, voting tendencies, and many other domains of life. They are multiply realizable, in the sense that they are differently inflected by varied cultures, which take the biologically given constraints and interpret and regulate them in diverse ways. They are also socially potent, with huge economic and political implications - just consider the extent to which the contemporary music industry, the fashion and cosmetics industries, commercial films, and politics depend on testosterone-powered aggression, dopamine-fueled infatuation, and oxytocin-driven bonding and suspicion. It is no wonder that religious worldviews have always attempted to regulate love and desire and narrate them in pro-social ways.

When cultural, often religious, narratives of love and desire work well, people young and old cultivate virtuous patterns of behavior that support group well-being. People internalize ideals that direct their intentions and their powers of agency to loving and desiring in specific ways, typically ways that match community expectations. To love otherwise than this is to embrace pain and confusion and either triggers reversion to the norm or else flight in search of a community with more compatible norms. The emotional potency of these love-and-desire systems is such that, when activated, they help us detect the socially constructed character of the social norms we employ to regulate love and desire. For instance, in a monogamous culture, the man who is unfaithful to his wife soon confronts, privately or publicly, the cultural norm that regulates sexual behavior, and he must decide whether to reject the norm or return to conformity with it. The woman who loves another woman in a social environment inhospitable to homosexuality sees the heterosexual norm as a looming, oppressive reality and will be forced to reject the norm secretly, reject the norm and relocate to a different community, or conform to the norm and suppress her natural feelings. The person with fluid sexual identity senses the binary gender norms of the home culture, whereas others may not even see them; the activation of love and desire in this person begs for a new type of social order where gender binaries are seen as unrealistic oversimplifications of a complex bio-psychosocial reality.

This neurobehavioral account of the human being's biologically embodied and socially embedded experience of love and desire has important implications for other classifications of love. Our diverse experiences make it obvious that there are many kinds of love and desire, and we human beings love to categorize difference in a never-ceasing quest to understand ourselves. The biologically grounded classification I offer here is far from 
the only way to look at things. Although it is true that all our experiences of love and desire will connect with the bodily realities I have described, and equally true that we are better off knowing than not knowing about the various love-and-desire systems, the ways we love are socially constructed and pull these pieces together in very different ways. Love of a pet, love of a friend, love of a child, love of a spouse, love of a sports team, love of a country, love of a moral ideal: it makes sense to pursue higher-order classifications of these wildly diverse realities to reflect the complex ways we put the atomic biological elements together in socially constructed patterns of love and desire. There is no need for an invidious biological reductionism here; biology constrains but does not determine human behavior. Likewise, there is no necessity to deny or delegitimate what we have discovered from the sciences about love and desire.

Similarly, there is no reason to think that the deliverances of the process of biological evolution in the form of the three (or four, if we include maternal love) love-and-desire systems should be normative for us. Social construction of reality includes social construction of the norms we rely on to catalyze moral consensus, social order, and civilizational stability. We can adopt norms that explicitly legislate against the reflexive outworking of the three love-and-desire systems. For example, we can articulate a radical form of agape love that explicitly resists the intensification of in-groupout-group boundaries associated with the bonding love-and-desire system (some neuroscientists even argue that unconditional love has not only a distinctive neural signature but special neural circuitry; see Beauregard et al. 2009). We can create a culture that ridicules infatuation as an abandonment of rational thought and a betrayal of our higher natures, thereby checking the infatuation love-and-desire system while still enjoying the intoxicating feelings it engenders in us. Or we can embrace a strictly celibate lifestyle in which sexual arousal is transmuted into love of some endorsed religious object and into loyalty to a fellowship of like-minded companions but ideally never expressed sexually, either physically or mentally. We establish such ideals all the time, pushing back against some of the deliverances of evolution and striving to realize imagined ideals that we deem superior to nature unchecked, unregulated, and unimproved - and, of course, we use what nature produces to refine what nature gives us as cognitive-emotional defaults. We must fight hard to push against the grain in this way, but with appropriate forms of social support and sufficient inner determination, we can often do it.

Individual differences matter here, as well. Not everyone loves well, or can love at all, in one or another sense of love. Men don't experience maternal love, for starters. Biological differences and psychological formation through traumatic experiences and cultural learning can also limit an individual's ability to engage in some kinds of romantic love or to achieve what some group might deem an ideal version of love. Just as personality characteristics are distributed normally across a population, so the capacity 
for love of various kinds varies from individual to individual. In relation to the sexual-attraction love-and-desire system, some people are essentially asexual, and love and desire do not operate in specifically sexual ways for them. In relation to the infatuation love-and-desire system, some people are too given to self-evaluation and judgment to surrender to the haze of delusional bliss on offer in the delirium of infatuation. In relation to the bonding love-and-desire system, some people's behavior patterns are so haphazard and so lacking in self-control that they can never build the trust required for bonding to grow. Every statement about human love and desire is a generalization, abstracting from the intricate details of human biology and psychology, yet rendering a serviceable approximation to messy reality. Just as it is foolish to pretend to eschew abstractions, we forget the downside of such abstractions at our peril.

Human beings are bad, often, as well as good, often. This is a serious consideration in love and desire. We desire things outside the boundaries prescribed by the social norms of our cultural worlds, creating internal psychic tension and, when self-regulation fails, social chaos. We have it within us to steal what we desire, love selfishly, and ruthlessly exploit people's vulnerabilities around love and desire. Amazingly, emerging from the swirl of culturally varied norms on our planet are a series of deep insights into love and desire that have the standing of widespread and nearly universal moral principles of love and desire that guide people away from the bad and toward the good, as defined within the scope of these principles. These principles show up in multiple wisdom traditions, despite being generated within cultures having distinctive behavioral and moral norms, confirming the depth of the corresponding insights. For instance, we know we shouldn't exempt ourselves or some special subset of people from the moral expectations we want to articulate. We know we should treat others the way we want to be treated. We know we should learn self-regulation to control desire. We know we sustain love by behaving in trustworthy ways. Monogamy might occur in only about 3 percent of mammalian species (Fisher 1992), but we know what behaviors promote happy monogamous relationships and what behaviors don't.

I employ the phrase "we know" here deliberately: these are forms of knowledge accumulated empirically from personal experience and codified in vast and long-lived traditions of moral wisdom. Knowledge of human behavioral patterns across cultures does not establish the "ought" of morality unaided - the slippery reasoning of the naturalistic fallacy is always near. Additional assumptions lock in the normative "oughts" atop descriptive information about human moral and immoral behavior we distill from world cultures and life experience. When we notice that we sometimes make exceptions - for instance, we exempt soldiers from certain widespread moral norms - we become aware of this additional layer of norm-making assumptions, which is almost invisible in most circumstances. Thus, neither the behavioral patterns made natural for human beings within the process 
of biological evolution within our planetary home, nor the moral principles we detect emerging within a host of varied human cultures, can determine moral norms by themselves. We can defer to them, but that deference expresses normative assumptions about the moral authority of nature and culture. We can resist them, but that resistance expresses normative assumptions about the moral authority of the human imagination as it envisions new ways of being human.

\section{Divine love and desire}

We have begun the promised shift downwards into the well of love and desire in the depths of nature itself. What shows up for human beings with regard to love and desire is one kind of guide to the axiological depth structures and flows of nature, but scientific inquiry presents us with other kinds of guides as well, as does critical theory from sociology and philosophy. Let's begin with critical theory's formalization of long-standing human insights into the social construction of reality.

Just as it is tempting to derive moral norms from descriptive information about nature (the naturalistic fallacy), so it is all too easy to impute to the depths of nature what we find emerging in human moral worlds (the projection fallacy). These two fallacies of moral reasoning are perpetually close at hand because we hesitate to accept full responsibility for adopting our preferred moral norms - indeed, we go to great lengths to evade awareness of this responsibility. This was one of Friedrich Nietzsche's passionate points, and the point of several moral philosophers contributing to our world's large philosophical literatures: we feel existentially disoriented with head-spinning nausea when we sense that the crystallizing of worldly facts into moral norms is the quintessentially human activity - that we alone bear responsibility for the moral norms we first create, then impose, and ultimately embrace as if they were imposed on us by an Other, be it heaven, God, or the spirits of the ancestors. This is the critical spine of the social construction of reality, and it doesn't apply merely to the emergence of traffic conventions; it has everything to do with the moral framing of love and desire.

A central commitment of any naturalistic moral philosophy is to accept this fact of human life and to embrace our responsibility for moral norms with no convenient deflections of responsibility, no evasions of the meaning of acts of norm creation, and no collapsing into either the naturalistic fallacy or the projection fallacy. We build our world, including the norms we employ to orient ourselves within it. Norm building is a group activity, so it is easy to miss the all-important element of human creation; it just feels as though moral norms hit us from outside. And they do hit us from the outside, of course, but only because we first externalized them and made them objective by imposing them at the group level so that subsequently they would be encountered as rules that we need to internalize in order to 
operate successfully within our group. Critical theory taught us to see the social construction of reality and generated irrefutable evidence of its presence and functions, which both ramifies and surpasses the same insight in its previous forms across cultures.

Do we make norms for love and desire? Yes, we do. We externalize behavioral expectations surrounding love and desire; we objectivate those expectations in human groups, we internalize the now-objective externalized rules; and we narrate the appearance of those norms in our lives as gifts from heaven, commandments from God, or wisdom from ancestors. They may be those things, in the demythologized, naturalistic sense of the phrases, but they are ultimately our creations, our constructions, and signs of our creaturely craving for control over anomic chaos. The raw materials for our constructions are the three (or four) neurobehavioral love-and-desire systems, along with the manifold culturally specific explorations of the multidimensional space of possibilities opened up by our biological natures. This is the domain of the biocultural, where biology can't be interpreted without culture and culture can't be understood without biology.

We are extremely creative in our biocultural constructions, no question. But those constructions are never random. For a socially constructed reality to survive the scrutiny that human beings reflexively apply to every act of self-and-world narration, we are inevitably forced to acknowledge the nondeterministic constraints of biology, even if we finally decide to contest or transcend those constraints. One day we may be able to deploy biotechnology to change our very brains and bodies so as to express the moral norms we prefer; for now, biology conditions and constraints but does not dictate or determine how we love and desire. Likewise, we are smart to respect the cross-cultural consensus on wisdom in relation to love and desire, because those discoveries were hard won and are probably as close to timeless human wisdom as our species possesses, but we are also smart to be suspicious of unstable generalizations masquerading as the wisdom of averages. Our journey through the multidimensional space of biocultural possibilities related to love and desire shows us that the biocultural is incredibly fecund, spawning pathways optimized for the survival and flourishing of groups that journey along them. In the patterns of similarity and difference that emerge as we compare those pathways, we detect the areas of strongest constraint, where there is cross-cultural consensus on moral principles related to love and desire, and the areas of weakest constraint, where the crosscultural diversity spreads in every direction like a veined network of river remnants fanning out over a plain.

This line of interpretation roots the emergence of human love and desire in the biocultural background of our species, going back millions of years. A naturalistic account of this emergence requires no postulates of purposeful teleologies or primal teleonomies or reflexive entelechies or gaiaic impulses that draw the cosmos toward the realization of desire and love, as if the process were designed or somehow guaranteed because of an ultimately 
purposeful power at work in the cosmic environment. On the contrary, this account of human wrangling with moral norms for love and desire makes perfect sense even if the universe is wholly accidental, fundamentally random, deterministically fated, or utterly meaningless in some global sense. We make meaning where we are, locally, and it is only our narrations of meaning that we project into the cosmos in search of plausibility. If we don't check them too carefully, they pass muster and we can carry on, sensing that our working norms for love and desire match the cosmos well enough for us to feel at home there. This is delusional thinking, however, even when it produces wonderful behavioral fruits. It can be challenged only by seeking comprehensive, unrelenting correction from what we discover about the world around us.

Nature is neutral to us, affording us possibilities to exploit and presenting dangers to navigate. Eat the wrong berry and we die, with nary a tear from Mother Nature. A large asteroid will wipe out most life on Earth, as has occurred several times before in the history of our planet, and there is no cosmic or divine memorial service - not for the religious naturalist, at least, and for the personal theist there is only a monumental, finally intractable theodicy problem, as the fantasy of a personal deity smashes to pieces on the rocks of reality. Suppose we narrate love and desire all the way into the depths of nature, making the ground of being look a lot like our morally normed human adventures in love and desire, and risking that appalling theodicy problem. In that case, for the religious naturalist, we not only fall prey to anthropomorphic wish fulfillment; we also minimize and neglect the miracle of nature in which spontaneity mates with law-like regularity to yield our planetary home and eventually human love and desire, in all its complexity, and we effectively evade responsibility for the social construction of love and desire in human life. Religious naturalism may be a false worldview, I allow - and to repeat, that's a debate for another place. But in rejecting personalist framings of love and desire in the entire cosmos, from its divine roots to its biocultural floral showings, the religious naturalist is not rejecting the importance of love and desire. On the contrary, the religious naturalist treasures love and desire all the more for rightly understanding the miracle of their emergence, the miracle of their biocultural conditions, and the miracle of our ability to create norms to conform with and to confound the default cognitive-emotional-behavioral love-and-desire impulses of our species. That kind of realism is all too rare in religion, and that kind of resistance to invidious reductionism is all too rare in religious and antireligious philosophy.

But might there be evidence beyond the questionable findings of needful human projection for something deep in nature that beckons cosmic reality to manifest love and desire? The pre-Socratic philosopher Empedocles discerned two fundamental dynamic principles in nature: love and strife. Might not he be correct, all these centuries later? Empedocles was right about the pair of dynamic principles, which we today would call attraction 
and repulsion, thinking especially of the electromagnetic force, but also of the other fundamental forces by analogy. But in naming the two fundamental forces love (philotes) and strife (neikos), Empedocles directly tied them to phenomena in the human sphere, which is misleading. Electromagnetic attraction and repulsion are conditions for atoms, molecules, chemistry, and biology, and thereby for love and desire-aversion, but it is an instance of the projection fallacy to impute to atomic and subatomic forces human-like feelings and motivations. We have had plenty of anthropomorphism in human efforts to ground love and desire in the wider cosmos - enough already. The micro-level forces that function as conditions for the emergence at the biocultural level of complex harmonies, and even of unruly chaos, should be appreciated without anthropomorphic distortion. What those fundamental forces are, ontologically speaking, is a first-rate mystery, but we get further by constructing empirically testable mathematical theories of them and running experiments to evaluate those theories than we do by giving free rein to our imaginative powers, piling trope upon trope in a desperate attempt to give cosmic significance to human experiences of human love and desire.

For the religious naturalist, therefore, love and desire have cosmic significance not because they were in some sense always there, within a creator God or any kind of natural entelechy, but because they emerge without collusion or design within the biocultural realm as a sign and an instance of the potent axiological possibilities in the very depths of nature. In this interpretation, there is no evading responsibility for the all-too-human construction of norms to manage love and desire. Nor is there any dimming of the luminous possibilities that lie before us. We can choose what love and desire will mean for us, constrained but never determined by biocultural givens, and inspired by pictures of an ever more just and verdant world.

\section{References}

Beauregard, Mario, Jérôme Courtemanche, Vincent Paquette, and Evelyne L. StPierrea. 2009. "The Neural Basis of Unconditional Love." Psychiatry Research 172 (2): 93-98. doi:10.1016/j.pscychresns.2008.11.003

Choi, Charles Q. 2011. “A Love-Hate Relationship?: 'Feel-Good' Oxytocin May Have a Dark Side.” Scientific American, January 12. www.scientificamerican.com/ article/a-love-hate-relationship.

De Dreu, Carsten K.W., Lindred L. Greer, Gerben A. Van Kleef, Shaul Shalvi, and Michel J.J. Handgraaf. 2011. “Oxytocin Promotes Human Ethnocentrism.” Proceedings of the National Academy of Sciences of the United States of America 108 (4): 1262-1266. doi:10.1073/pnas.1015316108

Fisher, Helen E. 1992. Anatomy of Love: The Natural History of Monogamy, Adultery, and Divorce. New York: W.W. Norton and Company.

Fisher, Helen E. 2004. Why We Love: The Nature and the Chemistry of Romantic Love. New York: Henry Holt.

Fisher, Helen E., Arthur Aron, and Lucy L. Brown. 2006. "Romantic Love: A Mammalian Brain System for Mate Choice." Philosophical Transactions of the Royal 


\section{Wesley J. Wildman}

Society of London B: Biological Sciences 361 (1476): 2173-2186. doi:10.1098/ rstb.2006.1938

Fisher, Helen E., Arthur Aron, Debra Mashek, Haifang Li, and Lucy L. Brown. 2002. "Defining the Brain Systems of Lust, Romantic Attraction, and Attachment." Archives of Sexual Behavior 31 (5): 413-419. doi:10.1023/A:1019888024255

Jankowiak, William, and Edward F. Fischer. 1992. “A Cross-Cultural Perspective on Romantic Love.” Ethology 31 (2): 149-155.

Wildman, Wesley J. 2009. Science and Religious Anthropology: A Spiritually Evocative Naturalist Interpretation of Human Life. London and New York: Routledge. doi:10.1111/j.1467-9744.2010.01171.x

Wildman, Wesley J. 2017. In Our Own Image: Anthropomorphism, Apophaticism, and Ultimacy. Oxford: Oxford University Press. doi:10.1093/oso/97 80198815990.003.0002

Zeki, Semir. 2007. “The Neurobiology of Love.” FEBS Letters 581 (14): 25752579. doi:10.1016/j.febslet.2007.03.094 